\title{
Nail Dystrophy in Patients with Atopic Dermatitis and Its Association with Disease Severity
}

\author{
Bo Young Chung, Yong Won Choi, Hye One Kim, Chun Wook Park \\ Department of Dermatology, Hallym University Kangnam Sacred Heart Hospital, Hallym University College of Medicine, Seoul, Korea
}

Background: Nail dystrophy arises from various inflammatory dermatologic diseases. However, there have been few reports on the prevalence of nail abnormality in atopic dermatitis (AD) or on the relationship of this condition with the severity of the disease. Objective: This study was intended to determine the prevalence and types of nail abnormalities associated with AD and to evaluate the relation between nail abnormalities and the severity of AD. Methods: AD patients aged 2 to 19 who visited the outpatient clinic were thoroughly examined for nail abnormalities. Demographic information was collected and eczema area and severity index (EASI) score for severity of AD were checked. Results: A total of 235 AD patients (children and adolescents) were investigated. There were $24(10.2 \%)$ patients with nail abnormalities: transverse groove (Beau's line) $(25.0 \%)$, nail pitting (16.7\%), koilonychia (16.7\%), trachyonychia (12.5\%), leukonychia $(12.5 \%)$, brachyonychia $(8.3 \%)$, melanonychia $(8.3 \%)$, onychomadesis $(8.3 \%)$, onychoschizia $(8.3 \%)$, and onycholysis $(8.3 \%)$. There was no statistically significant difference in the total EASI score associated with development of nail abnormalities $(p=0.236)$. However, when the EASI score was confined to the lower extremities, it showed a relation to the prevalence of toe nail dystrophy (odds ratio, $1.115 ; 95 \%$ confidence interval, $1.014 \sim 1.316 ; p=0.030$ ).

Received June 1, 2017, Revised August 16, 2017, Accepted for publication August 22, 2017

Corresponding author: Chun Wook Park, Department of Dermatology, Hallym University Kangnam Sacred Heart Hospital, Hallym University College of Medicine, 1 Singil-ro, Yeongdeungpo-gu, Seoul 07441, Korea. Tel: 82-2-829-5221, Fax: 82-2-832-3237, E-mail: dermap@daum.net ORCID: https://orcid.org/0000-0003-4512-8668

This is an Open Access article distributed under the terms of the Creative Commons Attribution Non-Commercial License (http://creativecommons. org/licenses/by-nc/4.0) which permits unrestricted non-commercial use, distribution, and reproduction in any medium, provided the original work is properly cited.

Copyright (c) The Korean Dermatological Association and The Korean Society for Investigative Dermatology
Conclusion: Nail abnormalities in $A D$ are thought to be caused mainly by pathologic change in the nail matrix region, and the EASI score confined to lower limbs, might be used as a predictor of toe nail changes in patients with AD.

(Ann Dermatol 31(2) $121 \sim 126,2019$ )

\section{-Keywords-}

Atopic dermatitis, Eczema area and severity index, Nails, malformed

\section{INTRODUCTION}

Nails are hard keratinized structures on the top surfaces at the end of fingers and toes. It is important that nails are not just shields for protection. They are active structures: finger nails grow $1.8 \sim 4.5 \mathrm{~mm}$ per month and toe nails about of half of that ${ }^{1}$. Nails often reflect pathologic features of adjacent tissue and various nail diseases are found in about $10 \%$ of patients visiting our dermatologic clinic and approximately $6.8 \%$ of infants had nail alterations ${ }^{2,3}$. Nail disorders are caused by various conditions. Infections such as periungual wart or herpetic whitlow, or onychomycosis and acute traumatic damages are obvious reasons. Some drugs (like chemotherapeutic agents) are associated with nail dystrophy because they act on rapidly proliferating organs. Systemic diseases such as anemia, Raynaud's disease, hepatic failure, chronic heart failure, renal failure, thyroiditis, inflammatory bowel disease, and chronic bronchitis also affect nail growth ${ }^{4}$. In addition, many dermatologic diseases including psoriasis, lichen planus, lichen nitidus, pityriasis rubra pilaris, alopecia areata, and Darier's disease are known to affect nails ${ }^{5,6}$.

Atopic dermatitis (AD) is a common skin disease characterized by chronic, relapsing forms of skin inflammation from a disturbance of epidermal-barrier function that cul- 
minates in dry skin ${ }^{7}$. It is known to be one of the main predisposing factors for chronic hand and foot eczema. According to a previous study on dermatologic diseases associated with AD in Korean, $6 \%$ of patients had hand or foot eczema. The prevalence was increased by age until 30 , showing $3 \%$ at ages $0 \sim 10$ and $7.9 \%$ at $21 \sim 30^{8}$. Another study reported approximately $58.9 \%$ of active AD patients had hand eczema and $16 \%$ of them have nail change ${ }^{9}$.

However, no large-scale studies have been reported here, focusing on nail problems associated with AD. Even so, some related cases have been reported: osteomyelitis on the distal phalanges of AD patients ${ }^{10}$ and onycholysis on atopic eczema treated with PUVA photochemotherapy ${ }^{11}$. A study involving a small number of childhood AD subjects showed higher prevalence of nail dystrophy (4 of 48 patients, $8.3 \%$ ) than did the control (1 of 89 patients, $1.1 \%$ ), although this was not statistically significant ${ }^{12}$.

The aims of our study were to determine the incidence and types of nail abnormalities associated with AD and to determine their relation to the severity of $A D$.

\section{MATERIALS AND METHODS}

\section{Subjects}

This cross-sectional study was conducted at Department of Dermatology, Hallym University Kangnam Sacred Heart Hospital, Seoul, Korea. Eligible participants included all AD patients ages 2 19 who visited the outpatient clinic of during January 2014 to April 2016. AD was diagnosed by dermatologists clinically according to the criteria of Hanifin and Rajka ${ }^{13}$. Patients were excluded who had been diagnosed for other diseases known to affect abnormal nails: 1) Systemic conditions such as anemia, Raynaud's disease, hepatic failure, chronic heart failure, renal failure, thyroiditis, inflammatory bowel disease, and chronic bronchitis; 2) Infectious disease such as onychomycosis, viral warts, and herpes infections; 3) Dermatologic diseases, including psoriasis, lichen striatus, lichen planus, lichen nitidus, pityriasis rubra pilaris, alopecia areata, and Darier's disease. One subject with a history of traumatic nail effects (from biting them) was also excluded.

This study was approved by the institutional review board of the Hallym University Kangnam Sacred Heart Hospital (IRB no. 2013-08-68) and was conducted in accordance with the Declaration of Helsinki. Written informed consent was obtained from all patients or their guardians.

\section{Evaluation of nail features}

In order to evaluate the nail abnormalities, patients had physical exams of all finger and toe nails by dermatolo- gists who checked their shape, color, and hardness. Clinical pictures were taken if any nail abnormalities were detected. Nail abnormalities were classified as: transverse groove (Beau's line), trachyonychia, leukonychia, koilonychia, onycholysis, nail pitting, onychoschizia, melanonychia, brachyonychia, and onychomadesis. Epidemiologic features such as age and gender were also collected.

\section{Clinical assessment}

The severity of the AD was assessed using the eczema area and severity index (EASI) score, which evaluates four clinical parameters: erythema, induration/papulation, excoriation, and lichenification on a $0 \sim 3$ scale within four defined body regions (head/neck, upper limbs, trunk, and lower limbs). The scoring was done by dermatologists ${ }^{14}$.

\section{Statistical analysis}

The results were expressed as 'mean \pm standard deviation.' The chi-square test for nominal variables and the Student's t-test for continuous variables were used to determine the significance of differences. The relative frequency of risk factors was analyzed by logistic regression using the backward model. Significance levels for all analyses were set at $p<0.05$. All statistical analyses were conducted using PASW Statistics 18.0 (IBM Co., Armonk, NY, USA).

\section{RESULTS}

\section{Demographic features of patients}

A total of 235 patients were recruited, of whom the average age was $7.43 \pm 4.92$. The average EASI score for all patients was $9.81 \pm 8.75$. The study population consisted of 123 male and 112 females (male to female ratio, 1:0.91). There was no difference on average age between genders but males $(11.82 \pm 11.03)$ had higher EASI scores than did the females $(7.68 \pm 4.55)$.

The EASI score and age showed a weak correlation in this study group, with total correlation coefficient $(C C=0.297$, $p=0.006)$, upper limb $(C C=0.239, p=0.029)$, and lower limb (CC, $0.325, p=0.003)$ all showing statistical significance.

\section{The prevalence and types of nail dystrophy}

The detailed data on the prevalence and types of the nail dystrophy are provided in Table 1 . Of the 235 AD patients, $24(10.2 \%)$ patients had nail abnormalities. Males showed more nail abnormalities on fingers and toes than female, with an odds ratio (OR) of 2.4 (not statistically significant). There were 15 patients with finger nail abnormalities, 9 males and 6 females. The average age was greater in patients with finger nail abnormalities $(10.13 \pm$ 
Table 1. Prevalence and types of nail dystrophy patients according to nail abnormalities

\begin{tabular}{|c|c|c|c|c|}
\hline Features & $\begin{array}{c}\text { Patients with } \\
\text { nail abnormalities }\end{array}$ & $\begin{array}{l}\text { Patients with finger } \\
\text { nail abnormalities }\end{array}$ & $\begin{array}{l}\text { Patients with toe } \\
\text { nail abnormalities }\end{array}$ & $\begin{array}{l}\text { Patients without } \\
\text { nail abnormalities }\end{array}$ \\
\hline Patients counts $(n=235)$ & $24(10.2)$ & $15(6.4)$ & $14(6.0)$ & $211(89.8)$ \\
\hline Sex (male:female) & $17: 7 \quad(p=0.056)$ & $9: 6(p=0.539)$ & $12: 2(p=0.029 *)$ & 106:105 \\
\hline Age $(y r)$ & $9.42 \pm 4.96\left(p=0.034^{*}\right)$ & $10.13 \pm 4.36\left(p=0.026^{*}\right)$ & $9.21 \pm 5.67 \quad(p=0.155)$ & $7.17 \pm 4.88$ \\
\hline \multicolumn{5}{|l|}{$\begin{array}{l}\text { Nail segment involved } \\
\text { Nail matrix }\end{array}$} \\
\hline Beau's line & $6(25.0)$ & $5(33.3)$ & $3(21.4)$ & \\
\hline Nail pitting & $4(16.7)$ & $4(26.7)$ & & \\
\hline Trachyonychia & $3(12.5)$ & $3(20.0)$ & $2(14.3)$ & \\
\hline Leukonychia & $3(12.5)$ & $3(20.0)$ & & \\
\hline Onycholysis & $2(8.3)$ & $2(13.3)$ & $2(14.3)$ & \\
\hline Onychomadesis & $2(8.3)$ & $2(13.3)$ & $1(7.1)$ & \\
\hline Onychoschizia & $2(8.3)$ & $2(13.3)$ & $2(14.3)$ & \\
\hline \multicolumn{5}{|l|}{ Nail bed } \\
\hline Koilonychia & $4(16.7)$ & $3(20.0)$ & $3(21.4)$ & \\
\hline Melanonychia & $2(8.3)$ & $2(13.3)$ & $1(7.1)$ & \\
\hline Brachyonychia & $2(8.3)$ & $1(6.7)$ & $2(14.3)$ & \\
\hline
\end{tabular}

Values are presented as number $(\%)$, number only, or mean \pm standard deviation. ${ }^{*} p$-value $<0.05$.
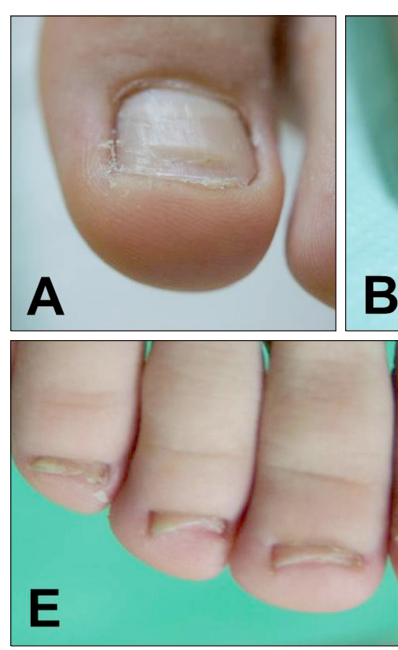
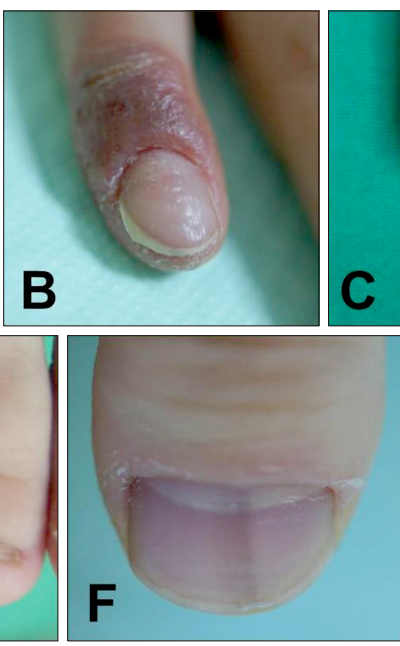
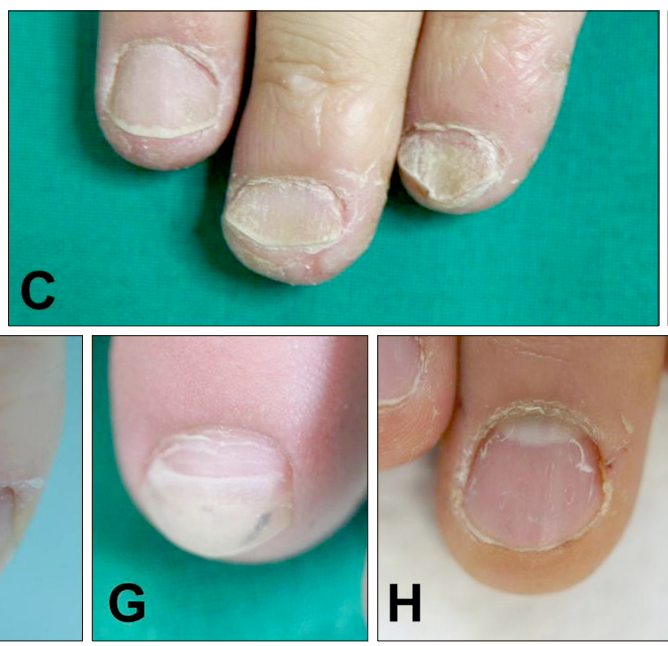

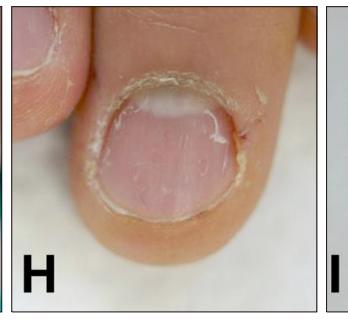

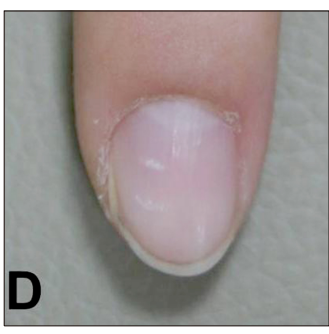

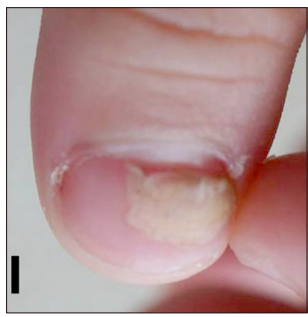

Fig. 1. Clinical pictures of nail abnormalities in patients with atopic dermatitis. (A) Transverse groove (male/12), (B) nail pitting (female/9), (C) koilonychia and trachyonychia (male/11), (D) leukonychia (male/10), (E) brachyonychia (female/15), (F) melanonychia (female/15), (G) onychomadesis (male/14), (H) onychoschizia (male/17), (I) onycholysis (male/11).

4.36) than in those without $(7.21 \pm 4.91)$, and this was a statistically significant difference $(p=0.026)$. Males had more finger nail abnormalities than did females but this was not statistically significant (OR, 1.395; 95\% confidence interval $[\mathrm{Cl}], 0.480 \sim 4.051 ; p=0.539$ ). There were 14 patients with toe nail abnormalities, 12 males and 2 females. The average age was higher in patients with toe nail abnormalities $(9.21 \pm 5.67)$ than in those without $(7.29 \pm 4.86)$, but the difference was not statistically significant $(p=0.155)$. Males had far more toe nail abnormalities than did females (OR, 5.634; 95\% Cl, $1.051 \sim 25.166$; $p=0.029$ ).
The nail abnormalities observed were classified as transverse groove (Beau's line) (Fig. 1A; 6 patients: $25.0 \%$ ), nail pitting (Fig. 1B; 4 patients: 16.7\%), koilonychia (Fig. 1C; 4 patients: $16.7 \%$ ), trachyonychia (Fig. 1C; 3 patients: $12.5 \%$ ), leukonychia (Fig. 1D; 3 patients: 12.5\%), brachyonychia (Fig. 1E; 2 patients: $8.3 \%$ ), melanonychia (Fig. 1F; 2 patients: $8.3 \%$ ), onychomadesis (Fig. 1G; 2 patients: $8.3 \%$ ), onychoschizia (Fig. $1 \mathrm{H} ; 2$ patients: $8.3 \%$ ), onycholysis (Fig. 1I; 2 patients: $8.3 \%$ ). There were 4 patients who had multiple types of nail changes; three of them had Beau's line. 


\section{Relationships of nail abnormality with EASI score and hand/foot eczema}

The detailed data on the relation of nail abnormalities with EASI score and hand or foot eczema are provided in Table 2. The average EASI score of patients with total nail abnormalities was higher than patients without $(11.80 \pm$ 8.31 vs. $9.30 \pm 9.50, p=0.236)$. The EASI score confined to upper extremity was $2.78 \pm 2.65$ for the finger nail change group and $2.24 \pm 1.72$ for the normal finger nail group (not statistically significant, $p=0.346$ ). The EASI score limited to lower extremities was higher in the toe nail change group $(7.23 \pm 5.64)$ than in those without them $(4.15 \pm 4.29)$, and this was statistically significant $(p=0.032)$. The logistic regression analysis, controlling for age and sex, showed statistical significance for toe nail changes in relation to EASI score of lower limbs (OR, $1.115 ; 95 \% \mathrm{Cl}, 1.014 \sim 1.316 ; p=0.030)$.

The prevalence of hand or foot involvement of AD patients with nail abnormality was 54.2\% (OR, 2.364; 95\% $\mathrm{Cl}, 0.923 \sim 6.055, p=0.091)$ and that of patients without nail abnormality was $33.2 \%(\mathrm{OR}, 0.423 ; 95 \% \mathrm{Cl}, 0.165 \sim$ $1.083 ; p=0.091)$. There was hand involvement of $A D$ in $40 \%$ of patients with finger nail abnormalities (OR, 1.778; 95\% Cl, $0.607 \sim 5.208, p=0.294$ ), and 42.9\% (OR, 6.156; $95 \% \mathrm{Cl}, 1.969 \sim 19.252 ; p=0.002)$ of patients with toe nail abnormalities had AD foot lesions. That is, nail change patients had more hand and foot eczema than those without nail change. Moreover, patients with foot eczema had higher incidence of toe nail changes (statistically significant).

The prevalence of finger or toe nail abnormalities in hand or foot eczema was $15.7 \%$ (13/83; OR, 2.364; $p=0.091)$ and that of patients without hand or foot eczema was $7.2 \%(11 / 152 ; O R, 0.236, p=0.091)$. Finger nail changes were seen in $9.1 \%(6 / 66 ;$ OR, $1.778 ; p=0.294)$ of hand eczema patients, and toe nail changes were seen in $20.0 \%$
(6/30; OR, 6.156; $p=0.032)$ in foot eczema patients. There was no statistically significant difference in EASI scores according to types of nail abnormalities.

\section{DISCUSSION}

This study was conducted to determine the prevalence and types of nail abnormalities in $A D$, and to evaluate the relation between nail abnormalities and the severity of $A D$. As it is well known, patients with AD have a high proportion of children and adolescents. In year 2014, the national prevalence of $A D$ in children (under age 19) was $5.8 \%$ and that of adults was $0.9 \%$. Actually, most of the patients are under the age of 20 in our outpatient clinic. Therefore, we targeted patients under 20 years of age and excluded onychomycosis because onychomycosis accounts for about $50 \%$ of nail disease, but it is very rare in children $^{15,16}$.

Of the 235 AD patients, 24 patients had nail abnormalities. There was no statistically significant difference in the total EASI score in relation to the presence of nail abnormalities. However, when the EASI score was confined to lower extremities, a relationship was shown with the prevalence of toe nail dystrophy.

Among the numerous diseases affecting nails, dermatologic ones make up the majority. Nail psoriasis accompanies about $10 \% \sim 55 \%$ in psoriasis patients and nail pitting is the most common feature ${ }^{17,18}$. Other nail changes that accompanied psoriasis included Beau's line, onycholysis, leukonychia, subungual hyperkeratosis, splinter hemorrhage, crumbling, onychomadesis, and red spot lunu$\mathrm{la}^{19}$. In psoriasis, nail involvement increases with age, duration, and extent of the disease. Moreover, the presence of psoriatic arthritis also caused diminished quality of life due to its high visibility ${ }^{20}$. Nail lichen planus occurs in $10 \%$ of patients with systemic lichen planus and may also appear in isolated nail lesions with absence of other cuta-

Table 2. Relation of nail abnormalities with EASI score and hand or foot eczema in atopic dermatitis

\begin{tabular}{lcccc}
\hline \multicolumn{1}{c}{ Features } & $\begin{array}{c}\text { Patients with nail } \\
\text { abnormalities }\end{array}$ & $\begin{array}{c}\text { Patients with finger } \\
\text { nail abnormalities }\end{array}$ & $\begin{array}{c}\text { Patients with toe } \\
\text { nail abnormalities }\end{array}$ & $\begin{array}{c}\text { Patients without } \\
\text { nail abnormalities }\end{array}$ \\
\hline EASI score & $11.80 \pm 8.31^{*}(p=0.236)$ & $2.78 \pm 2.65^{\dagger}(p=0.346)$ & $7.23 \pm 5.64^{\dagger}\left(p=0.032^{\S}\right)$ & $9.30 \pm 9.50^{*}(p=0.236)$ \\
Hand or foot involvement & $13 / 24(54.2)$ & $6 / 15(40.0)$ & $6 / 14(42.9)$ & $70 / 211(33.2)$ \\
of AD (location of eczema & $(\mathrm{H}$ or $\mathrm{F}, 2.364$, & $(\mathrm{H}, 1.778$, & $(\mathrm{F}, 6.156$, & $(\mathrm{H}$ or $\mathrm{F}, 0.423$, \\
lesion, OR, $\mathrm{Cl}, p$-value) & $0.923 \sim 6.055,0.091)^{\|}$ & $0.607 \sim 5.208,0.294)^{\S}$ & $\left.1.969 \sim 19.252,0.002^{\S}\right)^{* *}$ & $0.165 \sim 1.083,0.091)$ \\
\hline
\end{tabular}

Values are presented as mean \pm standard deviation or number/total number (\%). EASI: eczema area and severity index, AD: atopic dermatitis, OR: odds ratio compared to patients without nail abnormalities, $\mathrm{Cl}$ : $95 \%$ confidence interval, $\mathrm{H}$ : hand, $\mathrm{F}$ : foot. ${ }^{*}$ Total EASI score, ${ }^{\dagger}$ EASI score of upper extremities, ${ }^{\ddagger}$ EASI score of lower extremities, ${ }^{\S} p<0.05$, "OR compared to patients without finger or nail abnormalities, "OR compared to patients without finger nail abnormalities, ${ }^{*}$ OR compared to patients without toe nail abnormalities, ${ }^{\dagger+}$ OR compared to patients with finger or nail abnormalities. 
neous symptoms. Each of the nails can be affected separately or together. Thinning, ridging, and distal splitting of the nail plate are most common findings of nail lichen planus, and nail pterygium can be seen ${ }^{21}$. Nail changes in pityriasis rubra pilaris can be seen about $21 \%$ of patients, and is characterized by yellow-brown discoloration, subungual hyperkeratosis, nail thickening, and splinter hemorrhage $^{22}$. Darier's disease is an autosomal dominantly inherited disease characterized by greasy hyperkeratotic papules in seborrheic regions, nail abnormalities, and mucous membrane changes. Nail involvement occurred in $85 \% \sim 100 \%$ of the subjects and included: longitudinal red and/or white lines extending from the base of the nail across the lunula to the free margin of the nail, nail fragility, V-shaped notches at the free edge of the nail, longitudinal ridging of the nail, painful splits, and subungual hyperkeratotic fragments ${ }^{23,24}$. Onychomycosis can present onycholysis, subungual hyperkeratosis, nail-plate thickening, and leukonychia. AD patients are known to have higher susceptibility to viral and fungal infection due to altered immune responses and decreased T lymphocytes ${ }^{8,25}$. In this study, the above diseases were excluded, except for AD itself. Nail change may accompany AD but there is little information about the types of nail changes associated with AD. Compared to a reported prevalence of $8.3 \%$, in this study, $10.2 \%$ of $A D$ patients appeared to have nail changes $^{12}$.

Different nail dystrophies occur depending on the nail area in which the problem occurs. Eczematous change infiltrating the nail matrix can cause anonychia, nail pitting, trachyonychia, longitudinal ridges, transverse groove (Beau's line), onychomadesis, and onychoschizia ${ }^{26}$. Damage to the nail bed can cause brachyonychia, chromonychia, clubbing, koilonychia, subungual exostosis, yellow nail syndrome, onycholysis, and splinter hemorrhage ${ }^{27}$. In this study, the most common nail symptom was Beau's line which formed in $26 \%$ of patients with nail change. It is caused by decreased function of the proximal nail matrix and if the dysfunction persists over a few weeks, onychomadesis also appears (which formed $8.3 \%$ of nail abnormalities in this study). Three of four patients with multiple types of nail changes had Beau's line in common, in each case accompanied by koilonychia, nail pitting, and onychoschizia (Table 1). Along with Beau's line, a large portion of the nail dystrophies observed in this study, such as trachyonychia, pitting nail, and onychoschizia; have their origin in problems in the nail matrix. Regarding the results of this study, and the fact that other diseases causing nail abnormalities have biopsy-proven inflammatory effects on the nail matrix, it is reasonable to think that regional eczematous changes around nails cause the nail dystrophies observed in $\mathrm{AD}^{6,21,28,29}$. This might be caused by non-specific inflammation of the nail matrix, which then interrupts proper synthesis of the nails.

The average EASI score was higher in the nail abnormality group $(11.80 \pm 8.31)$ than in those with normal nails $\left(9.30_{ \pm}\right.$ 9.50), but the difference was not statistically significant. Because the EASI score is calculated based on erythema, induration/papulation, excoriation, and lichenification over the whole body area, finger and toe lesions contribute little to the score due to their small surface area. Moreover, because nails reflect their past like tree rings do, there may be no distinctive eczema involving the nail matrix when lesions are present. And since this study was cross-sectional study, only the lesion shown at the time of visit was able to be checked. Although it was not statistically significant, the EASI score of the upper extremities was higher in the finger nail abnormality group. More than that, the EASI score confined to lower extremities was higher in patients with toe nail abnormalities (statistically significant). Because older age and male gender contributed to higher EASI scores in the study population, logistic regression analysis was performed and the EASI scores of lower extremities and toe nail changes revealed a positive relation (OR, 1.115; 95\% Cl, 1.014 1.316; $p=0.030$ ). Patients with hand or foot eczema had higher rates of nail changes. Especially in foot involvement of AD, there was a significant correlation with toe nail abnormalities (OR, 6.257; $95 \% \mathrm{Cl}, 1.748 \sim 22.394, p=0.002$ ).

There are some limitations in this study. There was no control group from the general population to compare the prevalence of nail dystrophies. And skin biopsies were not performed to confirm histological features of nail apparatus due to patient's relatively young age and the possibility of permanent nail dystrophy. However, we were able to know which position of nail was abnormal through clinical appearance of nail. Nevertheless, there is significance as the first study to examine the type of nail dystrophy in AD and the association of nail change with the severity of AD. In this study, both EASI scores confined to lower limbs and $A D$ involvement of the feet showed positive relations to toe nail changes in this study. Toe nail changes might be predicted by the EASI score in the lower limbs in AD patients.

\section{ACKNOWLEDGMENT}

We thank the patients for granting permission to publish this information. This work was supported by the National Research Foundation of Korea (NRF) grant funded by the Korea government (MSIT) (No. 2018R1C1B6007998), and the Hallym University Research Fund (HURF-2017-52). 


\section{CONFLICTS OF INTEREST}

The authors have nothing to disclose.

\section{ORCID}

Bo Young Chung, https://orcid.org/0000-0002-2795-0140

Yong Won Choi, https://orcid.org/0000-0003-0607-5145

Hye One Kim, https://orcid.org/0000-0001-5846-0008

Chun Wook Park, https://orcid.org/0000-0003-4512-8668

\section{REFERENCES}

1. Kim J, Jeon IK, Kim YP, Kook YG. Study of the nail-II. Growth of nails in Korean. Korean J Dermatol 1983;21:297-305.

2. Cashman MW, Sloan SB. Nutrition and nail disease. Clin Dermatol 2010;28:420-425.

3. Sarifakioglu E, Yilmaz AE, Gorpelioglu C. Nail alterations in 250 infant patients: a clinical study. J Eur Acad Dermatol Venereol 2008;22:741-744.

4. Fawcett RS, Linford S, Stulberg DL. Nail abnormalities: clues to systemic disease. Am Fam Physician 2004;69: 1417-1424.

5. Kim IS, Lee JW, Park KY, Li K, Seo SJ, Hong CK. Nail change after chemotherapy: simultaneous development of Beau's lines and Mees' lines. Ann Dermatol 2012;24:238239.

6. Zhang JA, Yu JB, Li XH, Zhao L. Oral and cutaneous lichenoid eruption with nail changes due to imatinib treatment in a Chinese patient with chronic myeloid leukemia. Ann Dermatol 2015;27:228-229.

7. Bieber T. Atopic dermatitis. N Engl J Med 2008;358:14831494.

8. Lee HI, Han TY, Seo SJ, Kim DW, Kim MN, Kim MB, et al. Dermatologic diseases associated with atopic dermatitis in Koreans: multicenter study. Korean J Dermatol 2010;48: 191-197.

9. Simpson EL, Thompson MM, Hanifin JM. Prevalence and morphology of hand eczema in patients with atopic dermatitis. Dermatitis 2006;17:123-127.

10. Boiko S, Kaufman RA, Lucky AW. Osteomyelitis of the distal phalanges in three children with severe atopic dermatitis. Arch Dermatol 1988;124:418-423.

11. Morgan JM, Weller R, Adams SJ. Onycholysis in a case of atopic eczema treated with PUVA photochemotherapy. Clin Exp Dermatol 1992;17:65-66.

12. Kim JW, Park YM, Byeon DG. Evaluation of minor clinical features of childhood atopic dermatitis in Korea. Korean J Dermatol 1994;32:886-894.
13. Hanifin JM, Rajka G. Diagnostic features of atopic dermatitis. Acta Derm Venereol (Stockh) 1980;92:44-47.

14. Hanifin JM, Thurston $M$, Omoto $M$, Cherill R, Tofte SJ, Graeber $M$. The eczema area and severity index (EASI): assessment of reliability in atopic dermatitis. EASI Evaluator Group. Exp Dermatol 2001;10:11-18.

15. Lee JY, Yang HK, Kim M, Kim J, Ahn K. Is the prevalence of atopic dermatitis in Korean children decreasing?: National Database 2009-2014. Asian Pac J Allergy Immunol 2017; 35:144-149.

16. Gupta AK, Daigle D, Foley KA. The prevalence of culture-confirmed toenail onychomycosis in at-risk patient populations. J Eur Acad Dermatol Venereol 2015;29:10391044.

17. Sandre MK, Rohekar S. Psoriatic arthritis and nail changes: exploring the relationship. Semin Arthritis Rheum 2014;44: 162-169.

18. Youn Jl. Psoriasis in Korean. Korean J Dermatol 2012;50: 387-402.

19. Choi JW, Kim BR, Seo E, Youn SW. Identification of nail features associated with psoriasis severity. J Dermatol 2017; 44:147-153.

20. Augustin M, Reich K, Blome C, Schäfer I, Laass A, Radtke MA. Nail psoriasis in Germany: epidemiology and burden of disease. Br J Dermatol 2010;163:580-585.

21. Tosti A, Peluso AM, Fanti PA, Piraccini BM. Nail lichen planus: clinical and pathologic study of twenty-four patients. J Am Acad Dermatol 1993;28:724-730.

22. Sonnex TS, Dawber RP, Zachary CB, Millard PR, Griffiths AD. The nails in adult type 1 pityriasis rubra pilaris. A comparison with Sézary syndrome and psoriasis. J Am Acad Dermatol 1986;15:956-960.

23. Burge SM, Wilkinson JD. Darier-White disease: a review of the clinical features in 163 patients. J Am Acad Dermatol 1992;27:40-50.

24. Puri N. A clinical and histopathological study of Darier's disease. J Pak Assoc Dermatol 2011;21:230-234.

25. Scher RK, Tavakkol A, Sigurgeirsson B, Hay RJ, Joseph WS, Tosti A, et al. Onychomycosis: diagnosis and definition of cure. J Am Acad Dermatol 2007;56:939-944.

26. Nicolopoulos J, Goodman GJ, Howard A. Diseases of the generative nail apparatus. Part I: nail matrix. Australas J Dermatol 2002;43:81-90; quiz, 91-92.

27. Goodman GJ, Nicolopoulos J, Howard A. Diseases of the generative nail apparatus. Part II: nail bed. Australas J Dermatol 2002;43:157-168; quiz 169-170.

28. Sehgal VN. Twenty nail dystrophy trachyonychia: an overview. J Dermatol 2007;34:361-366.

29. Tosti A, Peluso AM, Misciali C, Cameli N. Nail lichen striatus: clinical features and long-term follow-up of five patients. J Am Acad Dermatol 1997;36:908-913. 